\title{
ANN WHITTLE
}

\section{ON AN ARGUMENT FOR HUMILITY}

Can we know anything about the intrinsic properties of particulars? Perhaps surprisingly, a number of philosophers from disparate backgrounds have felt compelled to deny that we have any such knowledge. According to Langton, for instance, one of Kant's central tenets is what she calls Humility, the thesis that we

are ignorant of the intrinsic properties of particulars. ${ }^{1}$ More recently, Russell, Maxwell, Blackburn and Lewis have each argued for some version of Humility. ${ }^{2}$

Why have these philosophers claimed that Humility is the only appropriate epistemic attitude? The exact arguments vary but, interestingly, a common line of reasoning can be traced from Langton's Kant to Russell and Maxwell through to Blackburn and Lewis. At the heart of these arguments, lie certain metaphysical considerations regarding the nature of properties and laws.

The aim of this paper is to look at some of the issues raised by this metaphysical line of argument for Humility. In section one, I shall begin by giving a detailed exposition of Lewis's argument, as I shall be focusing upon this. However, I shall also support the claim that Langton's Kant, Russell and Maxwell offer a similar line of reasoning, as I hope to show that the discussion of Lewis has wider implications for arguments further afield. In section two, I shall argue that, despite initial appearances to the contrary, the sort of Humility that results from Lewis's argument is not a serious epistemic limitation. So there is no need to reject this metaphysical framework because of its epistemological consequences. Despite this, however, I will argue in section three that the metaphysical framework 
proposed by the argument does have worrying metaphysical consequences. These, I'll suggest, provide a stronger reason for rejecting the metaphysical position underpinning Humility. In the final section, I shall put forward an alternative analysis, one which avoids both Humility and these unwelcome metaphysical consequences.

\section{THE ARGUMENT}

Lewis's paper, 'Ramseyan Humility', presents three distinct but related arguments for Humility. The first of these, Lewis calls, 'the permutation argument', for it rests upon the belief that properties could be permuted or swapped for each other, so that one property could suddenly stand in all the causal relations and make the causal contributions associated with another property, and vice versa. The other two arguments offered by Lewis are very similar. But instead of permuting properties with actual properties that play an active part in the workings of nature, they are permuted with 'aliens' or 'idlers', properties that don't exist in this world or are inactive here. Since the properties employed by the permutation argument are, as Lewis notes, less questionable than idlers and aliens, in what follows, I shall focus exclusively upon this argument.

Before expounding the permutation argument, however, it will be helpful first to uncover the background assumptions that it (and the other two arguments) requires. These can be stated as follows:

- $\quad$ Completeness: There is a complete, final scientific theory $\mathrm{T}$ (even if this is never discovered), which provides an exhaustive inventory of all the fundamental properties. 
- Ramsification: $\mathrm{T}$ can be stated by a Ramsey-sentence, in which all the fundamental properties mentioned in $\mathrm{T}$ are named by $\mathrm{T}$-terms. The $\mathrm{O}$ language is all the rest of our language, which is rich enough to express all possible observations.

- Quidditism: The acceptance of primitive property identity across possible worlds.

As these assumptions play a central role in the argument, it is worth saying a little more about each.

The assumption of completeness is central to Lewis's argument for Humility, partly because it is what gives Humility its punch. The thesis is not, after all, that we just don't know about the intrinsic properties of particulars. Rather it is that we are never going to be able to discover what these properties are. In order to convey this strong claim, Lewis has to say that the complete, final scientific theory cannot reveal the identities and natures of the most fundamental properties.

But what are these fundamental properties? In other papers, Lewis calls them the perfectly natural properties. Their definitive feature is that they "comprise a minimal basis for characterising the world completely" (Lewis 1983a, p.12). In his unpublished paper, Lewis makes it clear that these fundamental properties are simple entities. In other words, they are not composed of any further entities, and so they are not conjunctive, disjunctive or structural properties. This notion of a fundamental property plays a key role in Lewis's argument, as it links in with the assumption of completeness. A complete scientific theory would not be attainable if the universe turned out to be infinitely complex. Similarly, infinite complexity would exclude the possibility of ever providing a final inventory of the 
Published in Philosophical Studies 130 (2006)

fundamental properties. All that could be revealed would be structural properties which supervened on further structural properties and so on ad infinitum. If this, what Lewis calls "far-fetched possibility" were actually the case, ${ }^{3}$ it would be true to say that we could never have exhaustive knowledge of the intrinsic properties of particulars. But, as we'll see later, Lewis's argument for Humility wouldn't go through.

The second assumption, although seemingly innocent enough, is important in that it excludes certain possibilities. In particular, it rules out the possibility of gaining knowledge of the identities of fundamental properties via direct experiential contact. Lewis explicitly states that the fundamental properties must be named by theoretical terms. We do not have direct, observational experience of them, we only know that these properties are the occupants of certain theoretical roles outlined in the Ramsey-sentence.

We may try to question this by suggesting that we could have indirect experience of these fundamental properties by having experience of more complex macro-properties they are parts of, but the assumption seems reasonable enough. What is far more controversial is Lewis's further move: that Humility spreads to (nearly) all other properties, because they supervene upon the fundamental properties. Lewis's argument for this is that if we don't know the identities of the most fundamental properties, then we are not going to know the identities of more complex or structural properties that are constructed out of them.

This will raise the heckles of many. For instance, Campbell argues that experience confronts us with the properties underlying objects' tendencies. ${ }^{4}$ So even if we are ignorant of the intrinsic properties of micro-particulars, because we 
have experiential contact with the intrinsic properties of macro-particulars, we can have knowledge of their intrinsic properties. Lewis would deny this and argue that while we may know that a property presents itself in such-and-such a way in experience, this is just to know more about the causal role of that property. Our experience of the property of heat, for instance, does not reveal what heat is, namely, molecular motion. But even if we accept this controversial claim, it is still not evident that the spreading thesis follows. Non-fundamental properties may have identity conditions that are independent of the more basic properties they supervene upon. Thus, we may be able to identify macro-properties, despite being unaware of the identities of their subvenient properties. The conclusion of Lewis's permutation argument, however, is just that Humility holds of the fundamental properties, and for this, the only assumption required is that we do not have experiential contact with the fundamental properties. The further issues raised by his spreading thesis will be set aside here, even though it is required to get full-blown Humility.

The third and final assumption, that of quidditism, is crucial to Lewis's argument. It is motivated by his acceptance of 'the Principle of Recombination'. This states that "anything can coexist with anything else, at least provided they occupy distinct spatiotemporal positions. Likewise, anything can fail to coexist with anything else" (Lewis 1986a, p.88). Recombination forces us to deny that a property's nomological profile is essential to it. For although it may be a law that $(\mathrm{P} \rightarrow \mathrm{Q})$, if we grant recombination, because $\mathrm{P}$ and $\mathrm{Q}$ are distinct entities it is metaphysically possible that $\mathrm{P}$ could have occurred without $\mathrm{Q}$. So it is possible for $\mathrm{P}$ and $\mathrm{Q}$ to be governed by different laws. Why is this significant? Although it is a leap from this conclusion to quidditism (we have, for instance, to reject a 
Published in Philosophical Studies 130 (2006)

counterpart theory of properties), this view is bolstered by the lack of viable alternatives. Lewis assumes that the Ramsey-sentence of the complete scientific theory only offers information about the locational and nomological roles of the referents of the T-terms. So it is difficult to see what, other than the property's nomological role, could be appealed to in an analysis of a property's identity across possible worlds.

With these three assumptions in place, Lewis's permutation argument can be simply stated as follows:

(1) Suppose that the Ramsey-sentence has a unique actual realisation, in which properties $\mathrm{P}_{1}$ and $\mathrm{P}_{2}$ are the referents of the $\mathrm{T}$-terms $\mathrm{T}_{1}$ and $\mathrm{T}_{2}$.

(2) Granted quidditism, it is still possible for this Ramsey-sentence to have other realisations. For it is possible for any property to realise the nomological and locational roles associated with any other.

(3) Consequently, the properties which actually realise the roles definitive of $T_{1}$ and $\mathrm{T}_{2}$ could be permuted, so that the nomological and locational role occupied by $\mathrm{P}_{1}$ is now occupied by $\mathrm{P}_{2}$, and vice versa. ${ }^{5}$

(4) The Ramsey-sentence would be true regardless of whether property $\mathrm{P}_{1}$ or $\mathrm{P}_{2}$ realises the role of $\mathrm{T}_{1}$.

(5) Since the Ramsey-sentence of a theory commits us to all the same observable consequences of the original theory, any observation which is evidence for the complete scientific theory is also evidence for the Ramsey-sentence of that theory.

(6) Therefore, there is no observation which could have any bearing on the question of whether $\mathrm{P}_{1}$ or $\mathrm{P}_{2}$ is the actual realisation of the $\mathrm{T}_{1}$ role. 
(7) Therefore, although there is a contingent truth about which of the properties, $\mathrm{P}_{1}$ or $\mathrm{P}_{2}$, is the actual realisation of $\mathrm{T}_{1}$ 's role, we could never know it.

Lewis's argument is reminiscent of a line of reasoning offered some years earlier by Russell and Maxwell. Maxwell argues that "the reference of the term 'electron' is fixed (ontologically) by specifying the positions that electrons occupy in causal structural networks". But, he writes, while "The terms do refer to intrinsic properties...we do not know what the referents are". Science is said to "leave us completely ignorant as to what these intrinsic properties are" (1978 p.397). How does Maxwell come to this startling conclusion? The key principle he cites is this,

It is (logically) possible for different causal networks to have the same causal structure; or, in other words, one and the same causal structure may be realised in a number of different ways...God could have created a causal network such that it differed...only in that the positions occupied by a and b were occupied by different events (1978 p.390).

This echoes a line of thought put forward earlier by Russell. He writes,

So far as physics can show, it might be possible for different groups of events having the same structure to have the same part in the causal series. That is to say, given the physical causal laws, and given enough knowledge of an initial group of events to determine the purely physical properties of their effects, it might nevertheless be the case that these effects could be qualitatively of different sorts (1927 p.390).

In these passages, we again find an endorsement of quidditism. If all we can ever know is what causal roles these entities stand in, and this does not serve to tell us what entity we are talking about, then we are left with Lewis's conclusion that there are many facts about what these properties are that we cannot know. 
Published in Philosophical Studies 130 (2006)

Quidditism also plays a central role in the argument for Humility which Langton attributes to Kant. The master argument can be summarised as follows:

(1) There exist substances that have intrinsic properties.

(2) The substances that have intrinsic properties also have relational properties, among these are the causal powers that constitute phenomenal appearances.

(3) These relational causal powers cannot be reduced to the intrinsic properties of substances.

(4) Human knowledge depends upon our being affected by things.

(5) While substances that have intrinsic natures do affect us, it is not through their intrinsic properties that we are affected but through their causal powers.

(6) So humans can have no knowledge of the intrinsic properties of substances.

It is clear that this argument rests heavily on the third premise, a thesis suggested by Kant's claim that,

a substance never has the power through its own intrinsic properties to determine others different from itself...It only has the power in so far as substances are held together in a nexus through the idea of an infinite being (1986, p104).

According to Langton, passages such as this indicate that something like the following reasoning underlies Kant's acceptance of premise three: 
Published in Philosophical Studies 130 (2006)

(a) "A property is intrinsic just in case something could have it in the absence of other things - and in the absence of laws" (Langton, 1998 p.119).

(b) If the laws had been different, substances with the very same intrinsic properties would have had different causal powers.

(c) So causal powers are not reducible to the intrinsic properties of substances.

Although there are important differences between this argument and Lewis's, they are clearly similar. It starts with a claim about what we can know: Lewis says that we can only know about the nomological-locational structure of the most basic properties, while Langton's Kant claims that we can only be directly aware of the powers of substances - the ways in which they affect us. From this, we get to Humility in the same way: in both cases it is argued that this access to the causal role of a property, or to the causal powers of a substance, does not give us knowledge of the intrinsic properties of substances. For the causal structure associated with a property, or the causal powers of a substance, could remain unchanged despite wholesale permutation of the intrinsic properties. In what follows, then, although I shall be focusing exclusively on Lewis's argument for Humility, the discussion will also have implications for these other arguments which share the same format. ${ }^{6}$ I shall begin by looking at how serious the conclusion of Lewis's argument is.

\section{IS HUMILITY OMINOUS?}

Humility certainly looks bad. If we are ignorant of the most fundamental properties, upon whose base all other properties supervene, this seems a very 
Published in Philosophical Studies 130 (2006)

substantial limitation on our knowledge. But there is a strange anomaly between Langton's reaction to Humility and Lewis's. Langton writes,

If...the ground is distinct from the power, and contingently connected with it, then our orthodoxy is faced with a conclusion surprisingly similar to Kantian Humility...[Our name for the ground] becomes the name for a something-we-know-not-what - ominously similar to a Kantian thing in itself (1998, p.176).

Lewis, by contrast, takes a surprisingly laissez-faire attitude towards Humility, commenting: whoever told us that it is in principle possible to know everything?

Unfortunately, Lewis offers no more than this remark to explain why we shouldn't be perturbed by Humility. Indeed, he goes some lengths to show why his conclusion looks grave, arguing that we can't even identify those properties we know only as occupants of roles, since we cannot answer the question: which property occupies this role? This makes our ignorance look quite pernicious: if we can't even identify the property in question, then we don't seem to be in a position to know anything about it at all. In what follows, however, I will attempt to vindicate Lewis's laissez-faire attitude. ${ }^{7}$ This, I hope, will also serve to show why Lewis overstates the seriousness of his conclusion somewhat. Granted the assumptions Lewis is prepared to make, I shall argue that we can know which property occupies a certain role, because we are able to identify the properties in question.

What is it to identify an entity? According to Russell's Principle, as interpreted by Strawson and Evans, in order to identify a particular we require discriminating knowledge of it. In other words, "the subject must have a capacity to 
Published in Philosophical Studies 130 (2006)

distinguish the object of his judgement from all other things" (Evans, 1982 p.90). Strawson suggests that this discriminating knowledge takes one of three forms:

a person may be able to pick a thing out in his current visual field of perception. Or he may know there is a thing (not in his current field of perception) to which a certain description applies which applies to no other thing... Or he may know the name of a thing and be able to recognise it when he encounters it (Strawson, 1971 p.77).

Although this requires modifying slightly for properties, it is not difficult to see how it could be extended to this category. A person may be said to identify a property if they can pick it out in their field of vision, or they can recognize which particulars instantiate that property, or they are in possession of a description which singles it out from all other properties. In the case of fundamental properties, granted Lewis's assumption that we lack experiential contact with these properties, what we are interested in is the descriptive form of identification. Now throughout his paper, Lewis is adamant that the problem of Humility arises even if we suppose that the Ramsey-sentence has a unique realization. Although it is unclear quite what, in Lewis's framework, entitles him to this assumption, let's grant it for the sake of $\operatorname{argument}^{8}$ Once this is in place, it seems mistaken to say that we cannot identify the fundamental properties. For the Ramsey-sentence is uniquely realised, so its description of the $\mathrm{T}_{1}$ role serves to identify a unique property in the actual world.

Lewis, however, seems to think that something more is required: that we be able to single out the entity from all other actual and possible entities. But such a condition on identification seems too strong. Suppose, for instance, that I am a historian who knows all there is to know about Napoleon and this knowledge, we 
can safely assume, allows me to single out one person in history, namely Napoleon. Granted a certain view about the transworld identities of particulars, namely Haecceitism, this exhaustive knowledge of Napoleon would nevertheless fail to identify him. Why? Haecceitism states that two possibilities can differ just in the permutation of individuals. So everything could be qualitatively identical in two possible worlds, yet those worlds differ in that the person we name 'Napoleon' instantiates all the same properties that Nelson does in this world, and vice versa. ${ }^{9}$ Now this is a view which, although rejected by Lewis, is taken seriously by him. But if it were true then, on this theory of identification, we could never identify any particular via description. For all the qualitative facts that I know about Napoleon or any other particular could have been true of some other possible particular.

In light of this, the most obvious thing to do is to construe the requirement for identification to be the unique singling out of an entity in this world, which I think is what Strawson and Evans intended. But there is another alternative, again suggested by Strawson. He considers a scenario in which all the elements of our general description for, say, Napoleon, are reduplicated in another sector of the universe. ${ }^{10}$ Strawson argues that, in this case, we can still identify Napoleon, because although the general features of our description do not single out one entity, this uniqueness can be regained by a description which relates the entity in question to one which can be demonstratively identified. A similar move can be made here. Although, granted quidditism, there are other possible properties which could realise these roles, if we assume that these Ramsey-sentences are uniquely realised, then the descriptions still allow us to identify the properties in question. For while the general features of the description are shared by other possible 
Published in Philosophical Studies 130 (2006)

realisations, nevertheless, the properties in question are those which form part of the spatiotemporal world that I am currently aware of. So identification is ensured, because we have a special demonstrative access to the spatiotemporal world that these properties are part of.

In order to support the claim that we cannot even identify the most fundamental of properties, therefore, Lewis needs to impose more stringent conditions on what he takes to be the relevant notion of identification. There seem to be two possible avenues open here. First, Lewis could argue that although, in order to identify an entity, we do not need to be able to single it out from all possible as well as actual entities, we do need to be able to identify it via what Evans calls its "fundamental ground of difference", that which differentiates that entity from all other (actual) entities of the same type. ${ }^{11}$ So, as Lewis would deny that the fundamental ground of difference for a property is its locational or nomological role, we are not in a position to identify any of the most fundamental properties.

Again, however, this imposes too stringent a condition on identification. For instance, suppose that, following Adams or Swinburne, one thought that a particular's non-qualitative thisness constituted its fundamental ground of difference. ${ }^{12}$ These thisnesses, by definition, are not analyzable in terms of the object's relational or non-relational properties. So no general description citing qualitative features of the particular in question will be able to capture its thisness. This is bad news for the identification of particulars we can have no contact with, such as Napoleon. For our only way of identifying them is through descriptions, and these cannot capture a particular's thisness. Consequently, we cannot identify 
those particulars we are unable to contact, since we cannot identify them via their fundamental ground of difference.

An alternative strategy would be to claim that we are only able to identify an entity, via the descriptive method, if that description specifies something about that entity's intrinsic features, since then we can claim that the Ramsey-sentences fail to do this. Imposing such a constraint, however, appears ad hoc. Why suppose that an identification of an entity must always mention some of its intrinsic features? Why couldn't I identify Napoleon by simply listing the great number of things he had done? ${ }^{13}$ Unless a principled answer to this can be given, there is no need to impose a more stringent condition on identification than that stated in Russell's principle. $^{14}$

Lewis, then, seems to overstate his conclusion. To say that we aren't able to identify these fundamental properties is too strong. Given the notion of identification suggested, we can say which property, $\mathrm{P}_{1}$ or $\mathrm{P}_{2}$, occupies a certain role, because we have a theory which singles out a realizing property with suchand-such a role. So we know which thing we are talking about. The only thing we are in the dark about is what the realiser is like, independent of the role it occupies. However, because Lewis thinks that it is the property, considered apart from its nomological and locational role, that is responsible for its transworld identity, this means that we are also unaware of that aspect of a property that accounts for its identity in this and other possible worlds.

Where does this leave us? It is misleading to say that we don't know anything about the realiser property. Granted we have succeeded in identifying it, we can say something about what it's like, as we can say that it is the entity which 
Published in Philosophical Studies 130 (2006)

stands in such-and-such nomological and locational roles. But on Lewis's view, this fails to tell us anything about how the realiser is in itself. Following usage Lewis employs elsewhere, I am going to refer to this as the property's “intrinsic nature" (1986a, p.205), in order to distinguish it from the property qua its relational aspects. ${ }^{15}$ This terminology may seem rather inappropriate, for we standardly talk of intrinsic properties rather than intrinsic natures or aspects of properties. But if we are prepared to translate the criteria for intrinsic properties to their natures, then we'll see that it does make sense.

Characterisations of the intrinsic tend to fall into one of two categories. First, there is what has been called Kant's test. The basic idea behind this is that an intrinsic property is one which an object can instantiate regardless of what is gong on outside of it. ${ }^{16}$ Another way of putting the point is to say, with Kim (1982), that an intrinsic property is one which is compatible with loneliness, i.e. it does not require the existence of any contingent object wholly distinct from itself. ${ }^{17}$ The second test finds its origins in Moore, but it has become popular due to the work of Lewis. Moore writes that $\mathrm{P}$ is intrinsic iff "when anything possesses it, that same thing or anything exactly like it would necessarily or must always, under all circumstances, possess it in exactly the same degree" (1922, p.265). Lewis (1983a) reiterates this is his analysis of an intrinsic property as one that can never differ between duplicates. Kant's and Moore's criteria for intrinsic properties are not equivalent, since they have different extensions. For instance, 'being self-identical' counts as an intrinsic property on Kant's test, but not on Moore's. ${ }^{18}$ These differences can be set aside here, however, as all I wish to get across is the idea that the intrinsic nature of a property is that which remains the same no matter what 


\section{Published in Philosophical Studies 130 (2006)}

changes are made extraneous to it. So when asking what the intrinsic nature of a property is like, we are asking what a duplicate of that property would be like in worlds that are completely different from ours. This includes differences in laws, in Lewis's case, as duplicates of the realisers can exist in possible worlds with different laws.

How damaging is this conclusion that we are ignorant of the intrinsic natures of properties? Is this lack of access a significant limitation on our knowledge? The answer to these questions depends upon what we take the intrinsic natures of properties to be like. If we think that the intrinsic natures of these properties are simple, then we can say that these properties are the most fundamental entities, about whose natures nothing more instructive can be said. Explanations, after all, have to end somewhere. However, if we think of these properties as having complex natures, then we're much more likely to find Humility an ominous thesis, because then there are substantive facts about the natures of these complex entities that we cannot uncover.

But what does it mean to claim that these fundamental properties have complex natures? Usually, when we say that properties are complex, we tend to mean that they are structural properties. In other words, they are properties which are composed of other properties. Anything which instantiates a structural property must, as Lewis writes, "have proper parts; and there is a necessary connection between the instantiating of the structural universal by the whole and the instantiating of other universals by the parts" (1986b, p.81). But Lewis explicitly states that the fundamental properties, which are the concern of his argument, are not such properties. They are simple entities, so we cannot discover any more about 
Published in Philosophical Studies 130 (2006)

their intrinsic natures by analysing these properties into their component parts. If we ever reach this bedrock of fundamental properties, then we are at the terminus of scientific explanation. We have found the simple, unanalysable properties upon which all else supervenes.

This is the view, rightly or wrongly, that Lewis's argument is presupposing. Earlier, we noted that Lewis's assumption of a complete final theory requires that the universe is not an infinitely complex place. For, if it were, science would never reach completeness. What implications would this have? A form of Humility would be true, since we could never gain exhaustive knowledge of the intrinsic natures of properties. But this wouldn't be for the reason that Lewis cites, namely, that properties have intrinsic natures which we can never in principle find out about. Rather it would be because, no matter how far scientific theorising progressed, we would only ever uncover structural properties, which could be further analysed in terms of more basic structural properties, and so on ad infinitum. Given this, Lewis's argument would not gain the foothold it needs. It would be a mistake to think that any of the referents of the T-terms which, as Tterms, are known only as role occupants, would remain so. These T-terms might always become O-terms, given further analysis. For it would always, in principle, be possible to discover more about the intrinsic natures of these properties, by breaking them down into more basic (structural) properties.

In order for Lewis's argument to work, therefore, we need to suppose that these fundamental properties do not have complex structural intrinsic natures, in the sense that they cannot be further analysed in terms of more basic parts. How else, then, might these properties be thought of as having complex natures? An 
Published in Philosophical Studies 130 (2006)

alternative, which I shall outline in more detail later, would be to say that properties, while not being structurally complex, have complex causal natures. In other words, they are complex because they bestow an intricate nexus of powers upon the particulars that instantiate them. Lewis, however, cannot adopt this view, for he is committed to the Humean principle of quidditism. Because the property that realises a certain nomological role can realise different roles in different possible worlds, these causal features of a property cannot form part of its intrinsic nature. For this aspect of a property will differ between duplicates

So what could the intrinsic natures of these entities be like? The challenge for those who think that Humility is ominous is to say what characteristics the intrinsic nature of a property might have, our ignorance of which counts as a substantial limitation upon our knowledge. But philosophers who accept quidditism, and are thus vulnerable to Humility, do the reverse of this. For instance, Armstrong offers this characterization of a fundamental universal's "inner nature" or "quiddity" (1997, p.169):

we do not need any quiddity that goes beyond bare numerical identity and difference of simple universals (2004, p.146).

Similarly Lewis, when talking about the problem of temporary intrinsics writes, “There isn't much to the intrinsic nature of a universal. Maybe it's intrinsically simple, or maybe it's intrinsically composed, somehow, of other universals". ${ }^{19}$ The latter option, however, is ruled out in the case of fundamental properties, for we have seen that Lewis denies, and has to deny, that these are structurally complex entities, i.e. composed of other universals. 
Published in Philosophical Studies 130 (2006)

The similarity between Lewis and Armstrong's views here is no coincidence. Unless the thesis of infinite complexity is true, the fundamental properties are going to have to be simple entities, so they have no internal composition that can be utilized in order to explain why they differ. Similarly, there are no possible experiential differences between the properties that could tell them apart, and they cannot appeal to their differing nomological roles since, granted quidditism, this isn't part of the property's intrinsic nature. So Lewis and Armstrong are pushed into the view that these fundamental properties have simple, unanalysable natures which stand in such-and-such nomological and locational roles. I am not claiming that this conclusion is inevitable. There may be philosophers who accept Lewis's framework but who think that some further characterization of these intrinsic natures is possible. But then the onus is on them to say what sort of information this characterization will offer, and why we can't in principle find out about it. My point is only that, given the assumptions accepted by Lewis (and Armstrong), they seem to be left with fundamental properties whose intrinsic natures are merely numerically distinct from each other, for the simple reason that it is very unclear what else there could be. Besides, they give every indication that they accept this conclusion. So, given this, is Lewis's form of Humility ominous?

I suggest not. This conception of a property's intrinsic nature as a simple unanalysable entity, not only explains Lewis's unperturbed attitude towards Humility, it also illustrates that a serious form of scepticism isn't established by Lewis's argument. It isn't an exaggeration to say that not being aware of the intrinsic nature of a fundamental property, on this view, is no more worrying than 
Published in Philosophical Studies 130 (2006)

not being aware of, for instance, Napoleon's non-qualitative thisness, which, say some, accounts for his identity in this and other possible worlds. In both cases, we have a description which uniquely singles out the property and person in question. Furthermore, these descriptions provide an exhaustive account of all the scientific facts there are to know about this property, or, in the case of Napoleon, all the historical facts. For we have to grant that the intrinsic natures of these properties are simple, otherwise, there is nothing to prevent a T-term turning into an O-term when we discover more about its referent's parts. The only thing we don't know is the simple, unanalysable part of that property or particular that accounts for its identity in this and other possible worlds. But this isn't a very substantial restriction of our knowledge at all.

\section{PROBLEMS WITH QUIDDITISM}

If the argument of the last section is correct, then Lewis's (or Armstrong's) metaphysical analysis of properties needn't be rejected because of its epistemological consequences. Although the thesis of Humility, which this view is committed to, looks serious, when examined more closely, there is no reason to regard it as anything more than a rather esoteric, minimal epistemic limitation. In this section, however, I shall argue that there is a more serious worry in the offing. Although the epistemological cost of this analysis of properties is easy to bear, we also need to take into account its metaphysical implications.

According to both Lewis and Armstrong, there isn't much to the intrinsic natures of the most fundamental properties. But these simple intrinsic natures are nevertheless supposed to provide a minimal basis on which all else supervenes. 


\section{Published in Philosophical Studies 130 (2006)}

This gives rise to qualms about whether these entities are up to the task. Why is it that these properties have such differing nomological roles, when there isn't much to their intrinsic natures?

This rather vague worry becomes more pressing when we consider an argument employed elsewhere by Lewis against phenomenal properties. ${ }^{20}$ He asks us to suppose that phenomenal properties make a difference to what happens in the world, so that a certain taste brings about my expression of delight. In this case, he argues, the phenomenal property has a certain functional aspect which can be taught to the inexperienced, namely that this phenomenal property, call that $\mathrm{V}$, has such-and-such effects on me. However, if we grant the conclusion of the Mary's room argument, this functional description of the phenomenal property $\mathrm{V}$ does not exhaust the nature of that property. Since the functional aspect of V can be taught to the inexperienced, but there is a further aspect to these phenomenal properties which cannot be so conveyed. Let's call this the phenomenal aspect of V. Now, because the phenomenal aspect of $\mathrm{V}$ cannot be equated with its functional aspect, we can suppose that the phenomenal aspect gets permuted while the functional aspect remains invariant. To illustrate, take our phenomenal property $\mathrm{V}$ and call its functional aspect $\mathrm{f}$ and its phenomenal aspect $\mathrm{p}$. In our original example, $\mathrm{V}$, which has both $\mathrm{f}$ and $\mathrm{p}$, brings about my expression of joy. However, now suppose that the functional aspect of $\mathrm{V}$ remains unchanged despite a permutation in its phenomenal aspect, from $\mathrm{p}$ to $\mathrm{p}^{*}$. In this case, because the functional role of $\mathrm{V}$ is invariant, $\mathrm{V}$ will still bring about my expression of joy. But now we are supposing that the phenomenal aspect has completely changed. So this aspect of the property, 
be it $\mathrm{p}$ or $\mathrm{p}^{*}$, is epiphenomenal, since the result would have occurred so long as V's functional aspect remained the same.

It is not difficult to see why Lewis's argument against these phenomenal aspects or qualia is relevant to our case. The referent of the theoretical term $T_{1}$, say the property $\mathrm{P}_{1}$, has functional aspects as well as intrinsic aspects. In other words, the realising property doesn't just have an intrinsic nature, a way it is in itself, it also has complex functional features, like the fact that it stands in such-and-such nomological relations with these entities. Now the lesson of Lewis's argument for Humility, when it is properly understood, is that the intrinsic aspect of the property, like the phenomenal aspect of the phenomenal property, can be permuted. To illustrate, suppose that fundamental property $\mathrm{P}_{1}$, with its functional aspect $\mathrm{f}$ and its intrinsic aspect $i$, brings about a certain result. Since the intrinsic aspect of $\mathrm{P}_{1}$ cannot be equated with its functional aspect, it is possible to keep the functional aspect of the property the same while permuting its intrinsic aspect, say from i to $i^{*}$. $P_{1}$ could have brought about exactly the same result if it had incorporated functional aspect $\mathrm{f}$ and intrinsic aspect $\mathrm{i}^{*}$. Therefore, the effect only requires $\mathrm{P}_{1}$ 's functional aspect $\mathrm{f}$, its intrinsic aspect is irrelevant and so epiphenomenal.

The guiding thought behind both these arguments is that phenomenal aspects or intrinsic natures are causally irrelevant, because the effects they are associated with do not require them. Although the arguments do not rely upon Lewis's controversial counterfactual analysis of causation, it is crucial that we accept this counterfactual test as a (rough and ready) indicator of causal irrelevance: $\mathrm{P}$ is epiphenomenal with respect to $\mathrm{Q}$, when there is no counterfactual dependence of $\mathrm{Q}$ on $\mathrm{P} .{ }^{21}$ Leaving pre-emption and other tricky cases aside then, the 
claim is that $\mathrm{P}$ is shown to be causally irrelevant to $\mathrm{Q}$, if we could have held fixed everything in that scenario except $\mathrm{P}$, and still have got the same effect $\mathrm{Q}$.

At this point, one may object that the intrinsic natures of properties pass this test with flying colours. It is not possible to bifurcate a property into its functional and intrinsic features and then claim that only the former is efficacious, for a property couldn't have any functional features at all, and so be efficacious, if it didn't have an intrinsic nature. So these intrinsic natures are causally required for their effects. This objection, however, while useful in clarifying matters, fails to get to the heart of the matter. For the conclusion of the argument is not that a property's intrinsic nature per se is irrelevant to the causal workings of the universe. The claim is only that what this property's intrinsic nature is like, or its identity, is causally irrelevant to what it does, for the property's functional aspects will remain the same, no matter the identity of its intrinsic nature.

Still, it may be thought, something has gone wrong here. The mere fact that a property's functional role would remain the same even if there were different intrinsic natures doesn't seem to show that the intrinsic natures aren't doing causal work. Consider, for instance, a seeming analogous case in the philosophy of mind. The fact that the functional role of pain, at time $\mathrm{t}_{1}$, is realised by C-fibres firing and, at time $t_{2}$, is realised by D-fibres firing, clearly doesn't demonstrate that C-fibres firing is causally irrelevant at $t_{1}$. So how is the permutation of properties' phenomenal aspects/intrinsic natures supposed to demonstrate this?

In order to answer this objection, we must break the analogy by distinguishing between two different types of scenario. The first corresponds to the case of C-fibres firing. Here, there is more than one entity that could have brought 
Published in Philosophical Studies 130 (2006)

about that type of effect, because pain's functional role is multiply realisable. But this doesn't show that, at time $t_{1}$, the cause of Alice's arm jerking isn't the C-fibres firing. For, ignoring tricky cases of pre-emption and overdetermination, in those particular circumstances, Alice's arm wouldn't have jerked at $t_{1}$ without the $\mathrm{C}$ fibres firing. This kind of case differs significantly from the sort being envisaged in the arguments outlined above. There, the thought is that some particular aspect of the cause is causally irrelevant to the effect. Consider, for instance, a soprano, Ella, who causes a glass to shatter by singing the word 'shatter' at a high pitch. ${ }^{22}$ It wouldn't have mattered what word Ella sung, 'shatter' could have been permuted for 'foggy' or 'London' etc. and the effect would still have occurred, given that it was sung at the same high pitch. So, according to the counterfactual test for causal relevance, the meaning of the word is epiphenomenal for the shattering of the glass, since that effect would have occurred no matter the word's meaning.

If we accept, then, the counterfactual detector of epiphenomenalism, as Lewis himself does, quidditists are left with this conclusion: the identity of a fundamental property's intrinsic nature, or what it's like, is causally irrelevant to what it does. This is a problematic conclusion, for we tend to think that the most basic entities postulated by science will be causally efficacious entities par excellence, since they appear in the most fundamental explanations of the workings of the universe. But if this conclusion is correct, then the identities of these intrinsic natures are causally irrelevant to what goes on in the world. Even more puzzling than this, however, is the relationship between a property's epiphenomenal intrinsic nature and its functional aspect. Properties are said to have functional roles and so be able to contribute to the complicated causal nexus. But then these properties are 
also said to have intrinsic natures, whose identities are causally irrelevant to what goes on, and so, it would seem, irrelevant to the functional aspects of these properties. It thus becomes a pressing question how the inert intrinsic aspect of a property is related to its functional aspect.

In order to combat these difficulties, we need to defeat the epiphenomenal argument and show how the identities of the properties can be relevant to what goes on in this world. Fortunately, there does seem an avenue open here for those who endorse quidditism. For although they have to accept the possible permutation of properties' nomological roles, they do not necessarily have to claim that this permutation is nomologically possible. Instead, they could argue that it is only possible to permute the properties, given a change in the laws of nature. How would this help? If we allow that a law-like dependence between these intrinsic natures and certain effects suffices to show that the former are not epiphenomenal, then the argument is undermined. ${ }^{23}$ For all those possibilities where the laws are altered, and so the intrinsic natures permuted, are irrelevant to the question of whether the intrinsic natures are non-epiphenomenal aspects of their causes. What matters is whether these intrinsic natures are always required in worlds with the same nomological structure as ours, and they pass this test.

This move also enables the intrinsic natures of fundamental properties to pass the counterfactual test for causal relevance. The counterfactual we need to evaluate is this: if the intrinsic nature of property $\mathrm{P}_{1}$ had been permuted with the intrinsic nature of property $\mathrm{P}_{2}$, would the property still have had the same functional role? Plausibly, the answer to this is no, for all the nearest possible worlds where this permutation takes place are worlds in which the actual laws of 
nature obtain. So by permuting the properties' intrinsic natures, we permute their functional roles too, since the identity of these properties matters to which laws govern them.

Restricting permutation to worlds with the same laws, therefore, undermines the argument and also offers an intelligible explanation of the relationship between a property's intrinsic nature and its functional aspects. For although the intrinsic natures of properties are inert, once they are combined with the laws of nature, these intrinsic natures give rise to their properties' functional aspects and the whole array of causal activity is made possible. This solution, however, requires a certain view of laws - one which Lewis does not accept. On Lewis's Best Systems Analysis, laws are just those regularities which earn inclusion into the ideal system (which we can suppose can be stated in a Ramseysentence). This analysis serves the cause of Humean supervenience since,

History, the pattern of particular fact throughout the universe, chooses the candidate systems and the standards of selection do the rest (Lewis, 1986c p.127).

The relevant "standards of selection" are said to be simplicity and strength. The ideal theory "must be as simple in axiomatisation as it can be without sacrificing too much informational content; and it must have as much informational content as it can have without sacrificing too much simplicity" (Lewis 1983a, p.41).

On this view then, since laws are just those regularities which earn inclusion into the ideal system, in order for the laws of nature to be different, we have to suppose that the ideal system and its Ramsey-sentence is too. What implications does this have? Lewis's argument for Humility presupposes that we 
can hold fixed the Ramsey-sentence of the ideal theory, while permuting the intrinsic natures of $\mathrm{P}_{1}$ and $\mathrm{P}_{2}$. Consequently, this permutation must be regarded as nomologically possible. For in order for the laws to be different, the ideal theory and its Ramsey-sentence would have to be different also.

This means that Lewis cannot appeal to the view that the intrinsic natures of properties plus the laws of nature generate a property's functional aspects. For even when the laws remain constant, it is possible for the very same intrinsic natures to be combined with a variety of different functional features. As a result, Lewis bears the full brunt of the epiphenomenal argument. The intrinsic natures of properties are, in Sellars's words, "as substitutable for one another in any context as pennies" (1948, p.300). They can be permuted in worlds just like ours, so their identities are not 'making a difference' to the causal workings of the universe.

Even more problematic than this, however, is the relationship between the causally inert, intrinsic aspect of a property and its functional aspect. These epiphenomenal intrinsic natures seem incapable of explaining why a property is able to contribute to the causal workings of the world, and thus have the functional aspects that it does. Adding in the laws of nature is of no assistance here. The intrinsic aspects remain epiphenomenal since, given Lewis's theory of laws, no matter what the intrinsic nature of a property is like in worlds just like our own, its functional features could remain the same. The view we are left with is thus very peculiar indeed. We know that fundamental properties $\mathrm{P}_{1}$ and $\mathrm{P}_{2}$ have very different nomological roles, given the ideal theory, and so their functional features are central to explaining why everything else in the universe supervenes upon them. However, we cannot explain why these properties have the functional 


\section{Published in Philosophical Studies 130 (2006)}

features they do by either appealing to their intrinsic natures or to the combination of the laws and their natures. So Lewis's analysis leaves us in a quandary. It seems that these intrinsic natures have to be what account for the functional features of the fundamental properties (since laws are generated by a mere organization of the observational evidence); but at the same time, they are unable to.

The situation is much better for Armstrong, since he combines his quidditism with a strong view of laws. Armstrong argues that laws are secondorder states of affairs, such as $\mathrm{N}(\mathrm{F}, \mathrm{G})$, in which two first-order universals (in this case, $F$ and $G$ ) are related by a certain dyadic second-order universal, $N$, the relation of necessitation. According to Armstrong, it is a contingent matter which universals are related by the relation of necessitation. But if $\mathrm{N}(\mathrm{F}, \mathrm{G})$ obtains, then the first order regularity $\forall \mathrm{x}(\mathrm{Fx} \rightarrow \mathrm{Gx})$ has to obtain in that world too. ${ }^{24}$ There is a strong sense, then, in which the laws that obtain in a world govern the properties that fall under them. If the law pertaining to $F$ and $G$ holds in a world, then these properties cannot but behave in the way this law dictates.

This strong view of laws changes matters significantly, since in order to permute the properties in the Ramsey-sentence of the complete scientific theory, it isn't enough to simply exchange the intrinsic natures of properties $\mathrm{P}_{1}$ and $\mathrm{P}_{2}$. This won't do the trick because if the intrinsic nature of $\mathrm{P}_{1}$ is related, via the relation of nomic necessitation, to such-and-such effects, according to Armstrong's theory, $\mathrm{P}_{1}$ must have this nomic role. In order to change matters and permute the properties, therefore, we also need to change the laws or relations of necessitation between the properties. Only then will we be able to hook up the same intrinsic natures with different functional features. We've seen that this conclusion helps us defeat the 
Published in Philosophical Studies 130 (2006)

epiphenomenal argument. The argument assumes that the permutation of properties can occur in worlds just like ours, but we have to deny this if we endorse Armstrong's strong view of laws. As a result, it becomes implausible to say that these intrinsic natures are epiphenomenal. The identities of these intrinsic natures do matter to what goes on, since the laws govern properties with particular natures. So if a property had had a different intrinsic nature, and the laws remained the same, the property's contribution to the causal workings of the universe would change.

If we accept this strong view of laws, therefore, the problematic implications of quidditism are significantly reduced. But despite this success, I still think that we are better off rejecting quidditism. Why? On Armstrong's analysis, the intrinsic natures of properties $F$ and $G$ are no better suited to being governed by the actual law $\mathrm{N}(\mathrm{F}, \mathrm{G})$, than they are some possible law $\mathrm{N}(\mathrm{F}, \neg \mathrm{G})$. This is how it must be, as Armstrong wants to maintain quidditism and say that the same property can be governed by different laws. So, partly in order to ensure this, he claims that these properties' intrinsic natures differ only numerically from each other. But this analysis makes the intrinsic natures of the properties in question strangely irrelevant to the laws that govern them, and so also to the functional aspects of these properties. For there isn't anything about these properties' natures which makes it such that, in worlds like these, they occupy the nomological relations characteristic of this world. The laws are arbitrarily imposed upon these natures. Armstrong would no doubt respond by saying that we have to end explanations somewhere, and this is where we have to stop. But is it a satisfactory stopping point? In the next section, I shall suggest that there is a better one. 


\section{AN ALTERNATIVE}

The alternative analysis that I wish to propose states that we cannot divorce a property from what it does. Following Shoemaker, it claims that a property's identity is determined by its functional role, that complex set of causal powers a property (conditionally) bestows upon its bearers. ${ }^{25}$ A particular instantiates the property F-ness, for instance, iff that particular will, in virtue of instantiating that property, do $\mathrm{X}$, in circumstances $\mathrm{C}, \mathrm{Y}$ in circumstances $\mathrm{D}$, and so on. ${ }^{26}$ There couldn't be two instantiations of the same property that bestowed different functional roles upon their bearers. The alternative thus denies quidditism - the thesis that lies at the heart of the arguments for Humility put forward by Lewis and others. ${ }^{27}$ A property's identity across possible worlds is not primitive, as quidditism claims. For a necessary and sufficient condition for property identity across possible worlds is that two instantiations of the same property bestow such-andsuch a functional role.

Despite rejecting quidditism, the alternative I am proposing does not abandon the idea that properties are persisting states of particulars with natures that ground certain powers its bearer has. One way of spelling out Shoemaker's theory would be to argue that there is nothing more to an instance of a property than a certain complex functional formula being true of that particular. Properties have no natures that are responsible for the fact that these hypothetical conditionals hold of their bearers. But this is not the alternative I propose. ${ }^{28}$ Instead the idea is that properties (or their instances) are sui generis entities that are actual, persisting states of particulars. These instantiations of properties cannot be reduced to facts 
about what the particular would have done in such-and-such circumstances. But, nevertheless, the functional role that a property bestows upon its bearer is constitutive of that property, since it individuates that property in all possible worlds. So it is part of the essence or nature of a property that it bestow a certain set of complex (conditional) powers.

Are these natures intrinsic to their properties on this theory? Unfortunately, there is no clear-cut answer to this. The intrinsic nature of a property, roughly, consists in those features a property would have no matter its surroundings. Since Lewis and Armstrong think that we can separate the realiser from the nomological role it occupies, this means that there is a way that realiser would be even if it were transported to worlds with different laws. On the alternative view, however, this is not the case. Properties cannot be governed by different laws in different possible worlds, because there aren't any possible worlds where properties occupy different functional roles from the ones they occupy here. This means that, contra Lewis and Armstrong, the intrinsic nature of the realiser property could not remain invariant in worlds with different laws. But this does not show that the property's nature is extrinsic to it. On the contrary, it is precisely because the realiser's nomological role is inseparable from the property that its nature passes Moore's intrinsicality test. For any instance or duplicate of this realiser must have this nomological role, and so the realizing property "always, under all circumstances, possess it in exactly the same degree" (Moore, 1922 p.265).

It is not clear, however, that the nature of a property, on the alternative causal analysis, passes Kant's intrinsicality test. A particular can have a specific 


\section{Published in Philosophical Studies 130 (2006)}

functional role even if the occasions for its manifestations are never made actual, for the fact that the particular would do such-and-such in certain circumstances, does not require those circumstances to be actual. However, there may be occasions when the functional role demands the existence of something independent of the property, whatever the circumstances. Suppose, for instance, that there is a law which states that any particular that instantiates property $\mathrm{F}$ will also, in any circumstances whatsoever, instantiate property G. In this case, property F could not be instanced of a particular unless property $G$ was also instanced of that particular. Why does this matter? The instantiation of property $\mathrm{F}$ by the particular necessitates the particular's instantiation of property $\mathrm{G}$, in the sense that property $\mathrm{F}$ could not be instanced of the particular if this were not the case. So the nature of property $\mathrm{F}$, i.e. its power to bestow such-and-such a functional role onto its bearer, will not count as intrinsic on Kant's test, for it implies the existence of something outside itself, namely that the bearer also instantiates property $\mathrm{G}$.

It is unclear, therefore, whether fundamental properties are going to count as having intrinsic natures on the alternative analysis. For this depends both upon the details of our theory of intrinsicality and upon what the functional roles of these properties are. The usage of 'intrinsic nature' is far more clear-cut in Lewis's and Armstrong's analyses of properties, precisely because they deny that there are any necessary connections between distinct existences. So we can always think about what an entity would be like completely alone or unaccompanied. But the same is not true on the alternative causal analysis, since this claims that the natures of properties are dynamic or powerful, so they cannot be analysed independently of what they do. Fortunately, I don't think that anything important hangs on this for 
our present purposes. So in what follows, I shall just talk about the natures of the realising properties.

How, then, does this analysis avoid the problematic metaphysical implications of Lewis's and Armstrong's views? In the last section, we saw that Lewis was committed to the claim that the identity of the realiser, or what its intrinsic nature is like, does not make any difference to how it behaves. But the same is not true of the alternative. While it may be wrong to talk about their intrinsic natures, these properties are nevertheless actual persisting states of particulars with natures. Moreover, these natures are dynamic or powerful, as they enable their bearer to behave in certain ways. This suffices to undercut the epiphenomenal argument. We cannot permute the natures of two properties whilst holding their functional aspects fixed. For if we change their functional aspects, we thereby change their natures. So the identity of a property and its nature is not epiphenomenal to the effect. What the property's nature is, i.e. what set of powers it bestows upon its particulars, matters very much to what goes on in the world.

This analysis also avoids the problematic bifurcation between a property's intrinsic and functional aspects. We saw that Lewis was unable to account for the relationship between the epiphenomenal natures of properties and their functional features. But the alternative bypasses this problem in one of two ways. We could say, for the reasons given above, that the property does not have an intrinsic nature, but nevertheless it has an actual persisting nature, and this nature is dynamic. For in every world where that property exists, it is such that it bestows a certain set of powers onto its particulars. Alternatively, if we are satisfied by Moore's test, we can say that these fundamental properties have intrinsic natures, but once again 


\section{Published in Philosophical Studies 130 (2006)}

these are not causally inert. Either way, there is no mysterious relationship between a property's non-epiphenomenal, functional aspects and its epiphenomenal intrinsic nature that requires an explanation. The property is causally relevant to the causal workings of the universe because its nature (intrinsic or otherwise) is.

The case against Armstrong is weaker than that made against Lewis, since his view avoids epiphenomenal intrinsic natures and forges a more intelligible connection between the intrinsic and functional aspects of a property. However, Armstrong's claim that the internal natures of the most fundamental properties differ only numerically from each other remains problematic, since it means accepting that there is nothing about the natures of these fundamental properties which makes it the case that, in worlds like these, they occupy such-and-such nomological relations. The situation is very different if we endorse the alternative, causal analysis. On this view, the natures of the fundamental properties are not just numerically different, as Armstrong supposes. Rather, these natures have different powers, as they are responsible for particulars having diverse functional roles. Furthermore, the natures are intimately related to the laws which characterize how they behave. The reason why properties $F$ and $G$ are governed by the law $N(F, G)$ rather than the law $\mathrm{N}(\mathrm{F}, \neg \mathrm{G})$, for instance, is that these nomological relations are constitutive of F and $\mathrm{G}$ - the property F couldn't exist and this law fail to be true.

Now, in a sense, this may seem rather unsatisfactory, on a par with saying that opium has the power to cause drowsiness because it has a dormitive virtue. But, remember, we are supposing that we have come to the end of scientific explanations, to the entities upon whose shoulders all other properties supervene but about which nothing more can be said. So at this point, we need to ask 
Published in Philosophical Studies 130 (2006)

ourselves this: Is it more intelligible to claim that the fundamental properties occupy these particular nomological relations because they are dynamic entities, whose powers to stand in such-and-such relations are constitutive of their natures? Or, should we rather suppose that there is nothing about the natures of these properties that fits them for standing in the actual nomological role of this world, since these natures are only numerically distinct from each other, and so can be governed by any number of different laws? I leave this to the reader to decide.

What becomes of Humility on the alternative analysis? I have already argued that the form of Humility established by Lewis is not a serious form of scepticism. In section two, we saw that if we grant Lewis's assumptions, we can identify the most fundamental properties and say which property occupies a certain role. The same is true on the alternative causal analysis. We can know which fundamental property is instantiated by a particular by knowing what that property enables the particular to do. Shoemaker's alternative, however, seems on firmer ground here than Lewis's. For although we granted Lewis's assumption that these Ramsey-sentences are uniquely realised, it is unclear quite what, in his framework, justifies this. The causal analysis, however, has something more to say here. For on this view, if an instantiation of a property bestows the same functional role upon its bearer, it is an instantiation of the same property. So two instances with stand in such-and-such nomological relations are going to be instances of the same property.

Can we know anything more about the properties than this? In particular, can we know anything about what the natures of these realisers are like? At this point, the alternative analysis does have something more to say. On Lewis and 
Published in Philosophical Studies 130 (2006)

Armstrong's accounts, we can know something about what these realisers are like by knowing about what they do. But this doesn't form any part of the essence of the property, nor its intrinsic nature. The reason for this is given in the permutation argument. We can know what role a property occupies, but still be oblivious of the nature of that realiser. For the realiser of a certain role can be permuted with the realiser of any other without this making the slightest difference to the nature of that property. This possibility is excluded on the alternative analysis. We cannot change the functional role of a property without thereby changing the nature of the realiser. So knowing what powers the property bestows is to know the nature of the realiser.

No doubt some may feel that there is still some residual remainder, something hidden from the eyes of science, namely, the entity that bestows suchand-such powers onto its bearer. Part of the response to this worry is to remind ourselves why such ignorance is not important. In the case of complex properties, we can discover additional information about their natures by breaking them down into their component parts. But we are dealing here with the most simple and fundamental of properties, so there is no need to assume that the same must be the case. To think otherwise, is perhaps mistakenly to think of properties as akin to mini-particulars, with many-propertied natures that we can find out about. These instances of properties aren't thing-like, but rather ontologically dependent "ways that things are" (Armstrong, 1997 p.25). This isn't all that can be said, however. On the alternative causal analysis, it is simply false to say that we can't know anything about the entity that bestows such-and-such powers. For we find out about the nature of this dynamic entity by discovering what it enables its bearer to do. If 
Published in Philosophical Studies 130 (2006)

Shoemaker is right then, there is no need for Humility, even when it comes to the most fundamental properties of particulars.

\section{CONCLUSION}

Humility, in Lewis's hands, is not as bad as it looks. Moreover, even if the arguments of Russell and Maxwell or Langton's Kant do result in a more pernicious form of scepticism, still, those arguments can be undermined because of their reliance on quidditism.

But is quidditism rejectable? The metaphysical implications of this view vary, depending upon the theory of laws that accompanies it. Given Armstrong's strong view of laws, quidditism renders the link between the intrinsic natures of properties and the laws that govern them inexplicable. But, in Lewis's hands, the ramifications are far worse, since his view of laws allows for permutations of properties within nomically possible worlds. The identities of the properties which "comprise a minimal basis for characterising the world completely", thus become irrelevant. ${ }^{29}$ They are as "substitutable as pennies" for each other and so epiphenomenal. ${ }^{30}$ By rejecting quidditism and adopting the alternative proposed, we thereby defeat the argument for Humility and, more importantly, avoid these problematic metaphysical consequences. On the proposed alternative, properties have dynamic natures. They are not epiphenomenal, and so their identities are crucial to the complete scientific theory of the universe. ${ }^{31}$

\section{NOTES}


See Langton (1998). Humility invokes the notion of an intrinsic property, about which more shall be said later. But until then, the notion that I shall employ throughout is that of a property which can never differ between duplicates, or which a particular can instantiate regardless of what goes on outside of it.

2 See Russell (1927), Maxwell (1978), Blackburn (1990) and Lewis (unpublished manuscript).

3 See Lewis (1986b, p.86). Lewis reiterates the claim that this is a farfetched possibility in his unpublished work, although he admits that he doesn't know what to say to someone who dissents from this judgement. For a voice of dissent, see Schaffer (2003).

$4 \quad$ Campbell (2002). Others philosophers have followed Russell in thinking that we only have knowledge of the intrinsic character of the phenomenal or experiential world (see, for instance, Strawson 1980 and Blackburn 1990). Russell explicitly denies that this gives us any knowledge of the intrinsic character of the causes of our experiences, all we can infer from these experiences is the structure of the external world (see, for instance, Russell 1927, chapter 37).

5 Lewis restricts this permutation to properties with the same -adicity. So only two monadic properties, for instance, or two relational properties could be permuted.

There are other arguments which rely on quidditism and seek to establish some form of Humility. Blackburn, for instance, writes "Perhaps there is a possible world just like ours, not only in surface appearance, but in all that physics could ever discover, in which the dispositions have different categorical grounds, $G^{1}$. Perhaps in our world $\mathrm{G}^{1}$ supports dispositions on Mondays and Wednesdays, while G supports them on the other days" (1990, p.256).

7 Langton argues that Lewis and others who accept his contextualist theory of knowledge need not be concerned by the conclusion. For our lack of knowledge can be remedied by "Carelessness and inattention, as Hume advised. Forget the permutation argument" (Langton 2004, p.135). I hope to show, however, that there is an alternative strategy, which does not rely upon such a contentious theory of knowledge.

8 If unique realisation isn't assumed, then our epistemic situation with regards to the intrinsic natures of particulars becomes more serious. For, given the theory of identification which I shall defend presently, it will turn out that we cannot identify the properties in question.

9 See Lewis (1986a, §4.4).

10 See Strawson (1959).

11 See Evans (1982, p.107).

12 See Adams (1979) and Swinburne (1995). Swinburne writes, "what makes it the individual it is is not solely a matter of its properties...It is something distinct from and intrinsic to each individual which has it" (1995, p.391). It is this something that is a particular's thisness, according to Swinburne, and its nonqualitative thisness according to Adams.

13 Furthermore, although most of our identifications will involve an appeal to the entity's intrinsic features, I shall argue that, on Lewis's view, the intrinsic natures of fundamental properties are simple. This, if correct, would explain why an identification of such an entity does not invoke its intrinsic features. 
Although Russell's principle is thought, by many, to impose too strong a condition on reference (see, for instance, Sainsbury 1985), this would not help Lewis, since his requirement seems to be far stronger than Russell's.

15 Using Lewis's talk of 'intrinsic natures' may seem rather idiosyncratic, as it is certainly not a phrase which appears often in Lewis's work, and not at all in 'Ramseyan Humility'. But I think this can be adequately accounted for by two points. First, Lewis claims that we cannot even identify the realiser properties, and so we cannot know anything at all about them. However, I have argued against this claim, thus creating a need (not recognised by Lewis) to distinguish between the realiser's functional role, which we know, from its other, intrinsic features. Second, Lewis does not want to commit himself to realism about properties (or their instances), but here I am assuming such realism, because I doubt that Humility is an issue for those who aren't realists (see footnote 19 on this).

It may be thought that these intrinsic natures would be better labelled "quiddities", following Armstrong (see, for instance, 1997, p.169). However, this terminology is usually associated with a view about the transworld identity of properties. Armstrong, for instance, characterises quiddities by likening them to a particular's haecceity or thisness. So a quiddity is that unanalysable feature of a property that accounts for its identity across possible worlds. Now although there is a clear connection because this and what I mean by 'intrinsic nature', they should be pulled apart because, first, one might think that properties have what Lewis calls "intrinsic natures" (1986a, p.205) and Armstrong "inner natures" (1997, p.169), even though one denied that this accounted for their identity across possible worlds (one might, for instance, hold a counterpart theory of properties). Second, the intrinsic nature of a property might consist of far more than a quiddity if, for instance, it is complex.

16 See Van Cleve, 1999 p.151-2. He calls it Kant's test because Kant used it to show that being left-handed or right-handed is not a matter of how it is related to other objects. This differs from Langton's definition of an intrinsic property, as one an object could instantiate "in the absence of other things - and in the absence of laws" (1998, p.119). But Langton does not directly attribute the additional "in the absence of laws" to Kant. Rather she suggests that this understanding should be viewed as implicitly motivating Kant, since it renders his claims consistent (see 1998, p.117). There is, however, a close connection between the two conceptions of intrinsicness mentioned by Van Cleve and Langton. For if the laws in question are Humean, or are thought of as imposed upon the properties, then those properties of the object which depend upon the laws will not count as intrinsic to their objects.

17 Lewis (1983b) points out that this is not extensionally adequate, because loneliness is a property which meets this criterion but is not an intrinsic property. Kim, however, still succeeds in capturing the essence of Kant's test. For another, more recent, development of this analysis of intrinsicality, see Vallentyne (1996).

18 This point is made by Dunn (1990).

19 Lewis (1986a, p.205). Matters will be different if we adopt set nominalism, for then the properties will not be ontologically unanalysable. Instead, the property instantiations that stand in such-and-such roles will be identified with members of particular sets of possibilia. There is nothing more to an instantiation of a property 
than this. I shall set aside nominalist views here, however, even though Lewis does not commit himself to a specific ontological position (see Lewis 1983a). But it is worth noting that what we say about the ontology of properties is going to make a difference to the form of Humility we are left with. If we opt for realism about universals or their instances, it makes sense to say that we don't know what the natures of these sui generis entities are like. But if the fundamental properties are natural sets of possibilia, then what we will be in the dark about is just which particulars in other possible worlds are members of the set of possibilia identified with property $\mathrm{F}$.

20 See Lewis (1988). Robinson (1993) discusses Lewis's argument and suggests its application to properties more generally. The present section elaborates upon Robinson's discussion by attempting to show that, if we adopt a certain view of laws, the epiphenomenal argument does pose a serious threat to quidditism.

$21 \quad$ Lewis clearly accepts this principle. For other adherents of this test see, for instance, Le Pore and Loewer (1987).

22 This example has been used by a number of philosophers, but the basic outline was first proposed by Dretske (1989).

23 See, for instance, Fodor (1990).

$24 \quad$ See Armstrong (1997). Armstrong's views have changed significantly since then (see Armstrong 2004), but here I am summarising his earlier work.

$25 \quad$ See Shoemaker $(1980,1981,1998)$. There are other analyses of properties that deny quidditism and offer a functional-style analysis. See, in particular, Ellis's dispositional essentialism (2001), a view which is also being developed by Bird in a series of papers (see, for instance, 2002, 2004).

${ }_{26} \quad$ As spelling out those circumstances will no doubt make appeal to further properties, the analyses will be open to the charge of circularity. But proponents of the view can avoid this in the way that functionalists in the philosophy of mind do, namely by formulating a mammoth theory in which all the predicates of properties appear, and then ramsifying that theory. This way, properties' predicates will get holistically defined.

27 Lewis does acknowledge that we can evade Humility by rejecting quidditism, mentioning in a footnote the views of Shoemaker and others. Similarly, Langton also references those accounts which deny the "contemporary orthodoxy" i.e. the view that powers are not reducible to intrinsic properties (see, for instance, 1998 p.120). But I hope that this section will make it clear exactly how and why the alternative outlined avoids Humility, as well as explaining why it doesn't fall foul of the epiphenomenal argument.

${ }_{28} \quad$ One reason for this is because I am swayed by the intuition that there needs to be some persisting ground in the particular, something that is responsible for these complex hypothetical conditionals holding true of the particular. Another reason is because I think that spelling out this theory will leave us with a form of resemblance nominalism. Properties or their instances aren't sui generis items with natures on this view, rather they are reducible to sets of particulars all of which display a certain functional similarity.

29 Lewis (1983a, p.12).

$30 \quad$ Sellars (1948, p.300). 
31 I am very grateful to Stephanie Lewis, for permission to refer to "Ramseyan Humility" prior to its official publication. Many thanks also to Joel Smith, Keith Allen and an anonymous referee for their detailed comments. I presented a version of this paper at the Metaphysics in Science Workshop in Reading. I'd like to thank the British Academy for supporting that event and all the participants for their very useful comments. Finally, I wrote this paper during my Jacobsen Fellowship at the University of London. I am deeply indebted for all the help and support offered by members of that institution.

\section{REFERENCES}

Adams, R.M. (1979) 'Primitive Thisness and Primitive Identity', Journal of Philosophy, 76: 5-26.

Armstrong, D.M. (1997) A World of States of Affairs, Cambridge: Cambridge University Press.

Armstrong, D.M. (2004) 'How do Particulars Stand to Universals?' Oxford Studies in Metaphysics, 1:139-154.

Bird, A. (2002) 'On Whether some Laws are Necessary', Analysis, 62: 25770.

Bird, A. (2004) 'Strong Necessitarianism: The Nomological Identity of Possible Worlds', Ratio, 17: 256-276.

Blackburn, S. (1990) 'Filling in Space', Analysis, 52: 60-65.

Campbell, J. (2002) Reference and Consciousness, Oxford: Clarendon Press.

Dretske, F. (1989) 'Reasons and Causes', Philosophical Perspectives, 3: 47-76.

Dunn, M. (1990) 'Relevant Predication 2: Intrinsic Properties and Internal Relations', Philosophical Studies, 60: 177-206.

Ellis, B. (2001) Scientific Essentialism, Cambridge: Cambridge University Press.

Evans, G. (1982) The Varieties of Reference, Oxford: Clarendon Press.

Fodor, J. (1990) 'Making Mind Matter More', in his A Theory of Content and Other Essays (1990) Massachusetts: The MIT Press: 137-159.

Kant, I. (1986) Kant's Latin Writings, Translations, Commentaries and Notes, trans and ed. L.W. Beck in collaboration with M. Gregor, R. Meerbote and J. Reuscher, American University Studies, 9. New York: Peter Lang.

Kim, J. (1982) 'Psychophysical Supervenience', Philosophical Studies, 41: $51-71$ 
Langton, R. (1998) Kantian Humility, Oxford: Clarendon Press.

Langton, R. (2004) 'Elusive Knowledge of Things in Themselves', Australasian Journal of Philosophy, 82: 129-136.

Le Pore, E. and Loewer, B. (1987) 'Mind Matters', The Journal of Philosophy, 84: 630- 642.

Lewis, D. (1983a) 'New Work for a Theory of Universals', reprinted in his Papers in Metaphysics and Epistemology (1999) Cambridge: Cambridge University Press: 8-55.

Lewis, D. (1983b) 'Extrinsic Properties', reprinted in his Papers in Metaphysics and Epistemology (1999) Cambridge: Cambridge University Press: 111-115.

Lewis, D. (1986a) On the Plurality of Worlds, Oxford: Blackwell.

Lewis, D. (1986b) 'Against Structural Universals', reprinted in his Papers in Metaphysics and Epistemology (1999) Cambridge: Cambridge University Press: 78-107.

Lewis, D. (1986c) 'Postcripts to 'A Subjectivist's Guide to Objective Chance", in his Philosophical Papers II, Cambridge: Cambridge University Press: 114-132.

Lewis, D. (1988) 'What Experience Teaches', reprinted in his Papers in Metaphysics and Epistemology (1999) Cambridge: Cambridge University Press: 262-290.

Lewis, D. (unpublished manuscript) 'Ramseyean Humility', Melbourne University Philosophy Department Preprint.

Maxwell, G. (1978) 'Rigid Designators and Mind-Brain Identity', Minnesota Studies in the Philosophy of Science, 9: 365-403.

Moore, G. E. (1922) Philosophical Studies, Routledge: London.

Robinson, D. (1993) 'Epiphenomenalism, Laws and Properties', Philosophical Studies 69: 1-34.

Russell, B. (1927) The Analysis of Matter, London: Kegan Paul.

Sainsbury, M. (1985) 'Critical Notice of the Varieties of Reference', Mind 94: $120-142$.

Schaffer, J. (2003) 'Is There a Fundamental Level?’ Nous, 37: 498-517.

Sellars, W. (1948) 'Concepts as Involving Laws and Inconceivable Without Them', Philosophy of Science, 15: 287-315. 
Shoemaker, S. (1980) 'Causality and Properties', reprinted in Shoemaker's Identity, Cause and Mind (1984) Cambridge: Cambridge University Press: 206-232.

Shoemaker, S. (1981) 'Some Varieties of Functionalism', reprinted in Shoemaker's Identity, Cause and Mind (1984) Cambridge: Cambridge University Press: 261-286.

Shoemaker, S. (1998) 'Causal and Metaphysical Necessity', Pacific Philosophical Quarterly, 79: 59-77.

Strawson, P. (1959) Individuals, London: Methuen.

Strawson, P. (1971) 'Identifying Reference and Truth-Values', printed in his Logico-Linguistic Papers, London: Methuen: 75-95.

Strawson, P. (1980) 'Reply to Evans', in Philosophical Subjects, ed. Zak Van Straaten, Oxford: Clarendon Press: 273-282.

Swinburne, R. (1995) 'Thisness', Australasian Journal of Philosophy, 73: 389-400.

Vallentyne, P. (1996) 'Intrinsic Properties Defined', Philosophical Studies, 88: 209-219.

Van Cleve, J. (1999) Problems From Kant, Oxford: Oxford University Press. 